organizations of the United States (D. M. Ross), Britain (W. A. Langmead), France (P. Candes, J. M. Lavie, and M. Bricka), and Spain (E. R. Rodriguez and R. G. del Campo).

The book is a useful collection of papers and its value is increased by the adequate reporting of the discussion which followed each presentation.

D. Hughes

\section{PROGRESS IN OCEANOGRAPHY}

Progress in Oceanography

Vol. 1. Edited by Dr. M. Sears. Pp. vii +383 . (Oxford, London, New York and Paris: Pergamon Press, 1963.) $100 s$.

PROGRESS in Oceanography is intended to bo the first of an annual series of volumes with which it is hoped to keep oceanographers, and others interested in the sea, up to date with the rapidly expanding field of oceanography. The approach of the publishers is twofold; to presont reviews of the present status of currently important fundamental aspects of the subject, and to provide a medium for the publication of papers on original rosearch of wide interest, particularly thoso which are longer than those generally published in scientific journals. In addition, it is hoped to publish preliminary accounts of work in which new methods or approaches are used. Chapters lying within each of these headings are included in the present volume.

In the first chapter, E. Seibold describes recent work carried out at tho University of Kiel on the transport of near-shore sand. A well-documented review of the methods which have been used in the investigation of this problem is presented. An outline is also given of the procedures developed at Kiel for the study of sand transport; these include the examination of the structures and internal structuros of the sediments and their petrology. The rosults obtained by the application of these new techniques to the Baltic and North Seas will be of interest to both geologists and those engaged in coastal engineering.

Tho longest chapter in the book (124 pages) is essentially the Ph.D. thesis presented by D. C. Blanchard at the Massachusetts Institute of Technology. It is devoted to a rather lengthy and highly speculative quantitative study of the electric charge separating at the surface of the sea, and seems out of place in a book of this type.

The total suspended organic matter in the upper layers of the sea (in terms of carbon) appears to average about one-tenth of the total dissolved organic carbon. Zooplankton and fish represent only a small proportion of it (c. 2 per cent and 0.2 per cent respectively). The major part of the suspended matter ( 80 per cent) consists of detritus mainly derived from doad phytoplankton, together with lesser amounts of fæcal pellets and organic material derived from the land. Phytoplankton constitutes the remaining 20 per cent, amounting to an annual production of organic carbon in the hydrosphere of c. $3 \times 10^{10}$ tons. The importance of the role of the suspended matter in the sea in the marine food chain is only now being appreciated. Since much of the recent work on this subject has been carried out at the Nanaimo Biological Station of the Fisheries Research Bureau of Canada, the excellent review of this topic by T. R. Parsons is particularly timely. A very useful and thorough account is presentod of the determination and chemical composition of both phytoplankton and detritus. In a further section the geographical distribution of these types of particulate matter and of bacteria, fungi and yeasts is described. The chapter ends with a summary of the literature on the utilization of all these organic materials as sources of food for secondary producers. Our knowledge of this important topic is at present very fragmentary but is rapidly expanding, and it is to be hoped that the publishers will persuade Dr. Parsons to review the subject again in a few years time.

In a chapter entitled "The Salinity Problem", Cox has given an authoritative and critical, but rather irritatingly chatty, account of methods for the determination of ehlorinity and salinity which will be of interest to all occanographers. The section on conductivity salinometers is of particular value as it embodies an account of the author's personal experience with many types of these instruments, and gives a useful assessment of their precision.

The final chapter of the book is by F. C. Fuglister; it describes a comprehensive investigation of the Gulf Stream system undertaken in 1960 by the Woods Hole Oceanographic Institution. The larger part of the chapter is taken up with diagrams of sections and with tables of oceanographic station data which seem rather out of place in a book of this type.

The book is attractively produced and stoutly bound and should be in the library of every oceanographic institution. However, its contents are so varied in subject that it is doubtful whether any individual would wish to spend $£ 5$ on it for the one or two chapters which may bo of interest to him. The appearance of other volumes in this series will be awaited with interest. J. P. RmEX

\section{DEVELOPMENT OF MODERN DIURETICS}

\section{Diuretics}

Chemistry and Pharmacology. By George deStevens. (Medicinal Chemistry: a Series of Monographs, Vol. 1.) Pp. xiii + 186. (Now York : Academic Press, Inc.; London: Academic Press, Inc. (London), Ltd., 1963.) 7 dollars.

VER the past seven years important advances in medicinal chemistry have made available for clinical use a number of diuretics which are well tolerated and effective when given orally. In the previous thirty-five years, the mainstay of diuretic therapy had been the group of organic mercurial compounds of which mersalyl was probably the most popular in this country. Chance observation by Vogl, a third-year medical student in Vienna, had directed attention in 1919 to the diuretic potential of a mercurial drug which was being used for the treatment of syphilis. In spite of extended investigations, only a limited number of organic mercurials came into clinical use and among them none was entirely satisfactory when given other than by injection. While there were many miscellancous medicinal substances which could provolke a diuresis and some were active by mouth, there was no drug available other than an injectable organic mercurial that could be relied on for a potent and sustained diuretic action without more or less serious undesirable effects.

The discovery of the inhibitory action of sulphanilamide on carbonic anhydrase and the rational explanation of its acidotic effect led to the clinical testing of its diuretic activity in 1949. Krebs had meanwhile published an account of the carbonic anhydrase inhibiting activity of a number of cyclic sulphonamide derivatives. Further extensive work in several laboratories resulted in the marketing of acetazolamide, which deStevens calls "the first clinically effective, non-mercurial, orally active diuretic drug". Until about 1958, this drug was used as a reasonably satisfactory substitute for organic mercurial compounds, when a moderate diuresis was required. Its use was subject to the limitations that its effectiveness waned as the metabolic acidosis developed and that excessive potassium loss might occur during its use.

Other sulphonamides were investigated by Sprague and Beyer and their colleagues. This work led to the $m$-benzene 